\title{
NEW LOCALITY RECORDS AND ADDITIONAL COMMENTS ON THE LIFE HISTORY STAGES OF EPISTICTINA REICHEANA (GUERIN) (COLEOPTERA: CHRYSOMELIDAE: CASSIDINAE)
}

\author{
H.V. Ghate and S.P. Ranade \\ Department of Zoology, Modern College, Pune, Maharashtra 411005, India. \\ Email: hemantghate@hotmail.com
}

\begin{abstract}
Epistictina reicheana (Guerin) is being reported from new localities in Karnataka and Maharashtra states for the first time. Stereospermum colais (Dillw.), a Bignoniaceae tree, is found to be the host plant of this tortoise beetle. Record of this host plant is to be treated as the first Bignoniaceae host plant for an Oriental species of tortoise beetle. Additional information is provided about the ootheca, larvae and pupa.
\end{abstract}

\section{Keywords}

Tortoise beetle, Chrysomelidae, Cassidinae, Epistictina reicheana, Bignonaceae, Stereospermum colais, Maharashtra, Karnataka, India, life history

\begin{tabular}{lr}
\multicolumn{2}{c}{ Abbreviations } \\
H - Head & L - Lateral process \\
LL - Larval leg & LP - Lateral projections \\
PP - Pronotal process & S - Spiracle \\
SA - Supra anal process & TV - Tubercles on vertex
\end{tabular}

\section{Introduction}

Epistictina reicheana (Guerin) is a medium-size tortoise beetle with characteristic oval shape, elytral costae and a pattern of dark patches. Maulik (1919) had described the major morphological features of this insect, in detail, under the name Epistictia reicheana. This species is distributed in India, Nepal, Sri Lanka and Tasmania (Australia) (Borowiec, 1999). Within India it is known from the type locality of Visapur (State?) as per Maulik (1919), Kerala and Tamil Nadu (Takizawa, 1983). We now report this beetle from Bangalore (Karnataka: Coll. K.D. Prathapan, 31.xi.1999) and from Amba Valley (Dist: Raigad, Maharashtra: Coll. Vivek Gour-Broome and Sanjay Thakur, 17.x.2000). Amba Valley is an area situated in the Western Ghats. The valley receives about $3200 \mathrm{~mm}$ rainfall annually. The temperature range from $12.2^{\circ} \mathrm{C}$ to $36.8^{\circ} \mathrm{C}$ during the year. This area is presently being surveyed for biodiversity (with the financial assistance from the Rural Commune, Mumbai). Live beetles and few larvae were collected on Stereospermum colais, a Bignoniaceae plant found in Amba Valley. We kept these beetles alive under laboratory conditions for a few days on the leaves of the same plant and observed feeding. This confirmed that Stereospermum is the host plant. Not only that, two females deposited two oothecae on the upper surface of the leaves.

\section{Observations and Discussion}

Unavailability of food plant nearby did not allow us to study the complete life cycle this year. However, we have interesting additional information about the Amba Valley Epistictina. Interestingly, record of the host plant itself appears to be the first new information as no member of the Oriental tortoise beetles was known to be using a Bignoniaceae plant before (Prof. Borowiec, Poland, pers. comm.). In a recent paper, Buzzi (1994) has documented that 14 out of 170 tortoise beetles (i.e. 8.8\%) from the Neotropics feed on Bignoniaceae plants.

Regarding life history stages we have the following observations. The eggs are deposited on the upper surface of the leaf in the form of an oval mass or ootheca. Each egg is vertically placed in a sheet of brownish semi-transparent material secreted by the accessory glands, as in other Cassidinae. Many eggs (which are arranged in a monolayer) along with their semi-transparent coverings give rise to an ootheca. The ootheca appears as a yellowish, flat mass with wrinkled surface (Size: length $17 \mathrm{~mm}$ and breadth $7.5 \mathrm{~mm}$ in case of one ootheca. The other ootheca was almost half this size). There were more than 20 yellowish eggs in the larger ootheca (size of eggs: $1.5 \times 0.5 \mathrm{~mm}$, based on measurement of three eggs; entire ootheca was not disturbed to accurately count and measure all eggs, as we were interested in the larvae). 
In feeding trials, Epistictina imagines from Amba Valley were found to cut large areas of the leaf from the margin. The small larvae could only scrape the upper surface of the leaf but second instar onwards the larvae cut fine net-like holes in the leaf lamina. The fifth instar larvae were voracious feeders cutting large patches from the margin of the lamina.

The major morphological features of the larva and pupa are given by Takizawa (1983). Takizawa did not show or mention any colour pattern in the larva (but illustrated colour pattern of the pupa), however, there is a distinct pattern of dark patches.

The length of the three fifth instar larvae that we could study varied between $10-11 \mathrm{~mm}$ while breadth (excluding lateral processes) was $5 \mathrm{~mm}$. The larva shown by Takizawa measured only $6.5 \times 3.2 \mathrm{~mm}$. All the larvae appear dark brown but a distinct pattern can be observed. Head and legs are more dark coloured. The whole body of the larva is covered over by setae. The larval legs are as usual with a terminal chitinised claw but there are tufts of whitish hairs on either side of the claw laterally. Larvae carry faecal threads attached to the supra-anal spines through all the five instars but it appears (on the basis of 11 pupae that we observed) that these faecal threads along with larval skins are lost just before pupation. Last larval skin is however retained on the spines, during pupation, as mentioned by Takizawa.

The pupa has an average length $8.3 \mathrm{~mm}$ and breadth of $5.0 \mathrm{~mm}$ (based on measurement of three pupae) as compared to $7 \mathrm{x}$ $4.5 \mathrm{~mm}$ mentioned by Takizawa. The lateral processes of the pupa are triangular and are covered with microtubercles and setae. The pupa does not show urogomphi or apical processes that are commonly observed in other Cassidinae. There are no processes on the sixth and seventh abdominal segments, but in one pupa this site showed small tubercles. The eclosion takes place in about seven days (range 6 to 8 days) and, three to four days prior to eclosion, one can see dark black antennae and chitinised mandibles very well. The pupa is attached to the leaf surface and remains flat along with the leaf surface. However, when disturbed, it shows movement and it actually "stands up" to become vertical with respect to the leaf surface.

Overall, this beetle appears to show considerable variation in size and colouration, as pointed out by Maulik (1919). The beetles that were collected (and preserved) in Bangalore are smaller and paler with distinct dark patches; while those from Amba Valley are larger, with distinctly dark reddish ground colour of the elytra and indistinct dark elytral patches. The patches seem to merge with the ground coloration. The imagines in our collection also show considerable variation in length (mean 9.31, sd 5.93). It may also be pointed out here that the characters like shape and appearance of ootheca, larvae and their feeding, pupa and its behaviour upon disturbance, and apparently monophagous nature of larvae and imagines in case of Epistictina are very similar to other beetle, namely Craspedonta leayana (Latreille), that we have studied in Pune.

\section{Acknowledgements}

The authors are thankful to Dr. Prathapan (UAS, Bangalore), Mr. Sanjay Thakur and Mr. Vivek Gour-Broome (of Kalpavriksh, Pune), for collecting the beetles and sharing relevant data. VGB also identified the plant. We are grateful to The Rural Communes, Mumbai, for financial support to the Amba Valley Project. The authors are indebted to Prof. Lech Borowiec, Wroclaw, Poland, for confirming our identification as well as for constant encouragement and help in our work on these interesting beetles. Over the years we have benefited immensely because of this continuous interaction with Prof. Borowiec. We also thank the authorities of Modern College, Pune, for facilities.

\section{References}

Borowiec, L. (1999). A World Catalogue of the Cassidinae (Coleoptera: Chrysomelidae). Biologica Silesiae, Wroclaw, Poland, 476pp.

Buzzi, Z.J. (1994). Host plants of Neotropical Cassidinae, pp 205212. In: Novel Aspects of the Biology of Chrysomelidae. Kluwer Academic Publishers, The Netherlands.

Takizawa, H. (1980). Immature stages of some Indian Cassidinae (Coleoptera: Chrysomelidae). Insecta Matsumurana new series 21: 19-48.

Takizawa, H. (1983). Chrysomelid-beetles of India in the collection of the National Institute of Agricultural Sciences, Tsukuba. (Coleoptera). Entomological Review of Japan 38(1): 65-79.

Maulik, S. (1919). The Fauna of British India including Ceylon and Burma. Coleoptera: Chrysomelidae (Hispinae and Cassidinae). Taylor and Francis, London, 439pp.

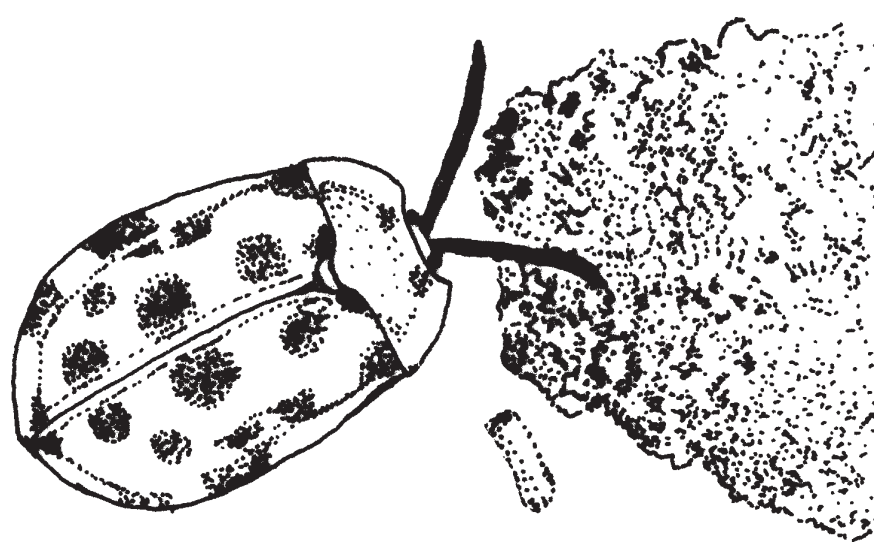

Figure 1. Epistictina rechieana adult with ootheca 
$\mathrm{L}$ - Lateral process

S - Spiracle

SA - Supra anal process

Figure 2. Dorsal view of the larva covered by setae

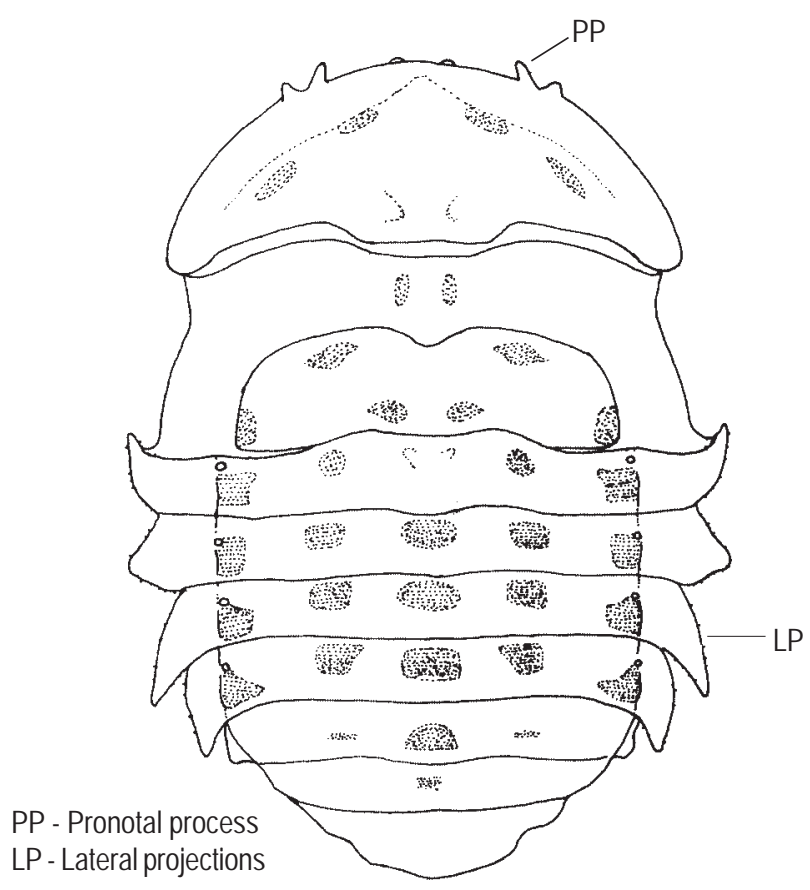

Figure 4. Dorsal view of the pupa

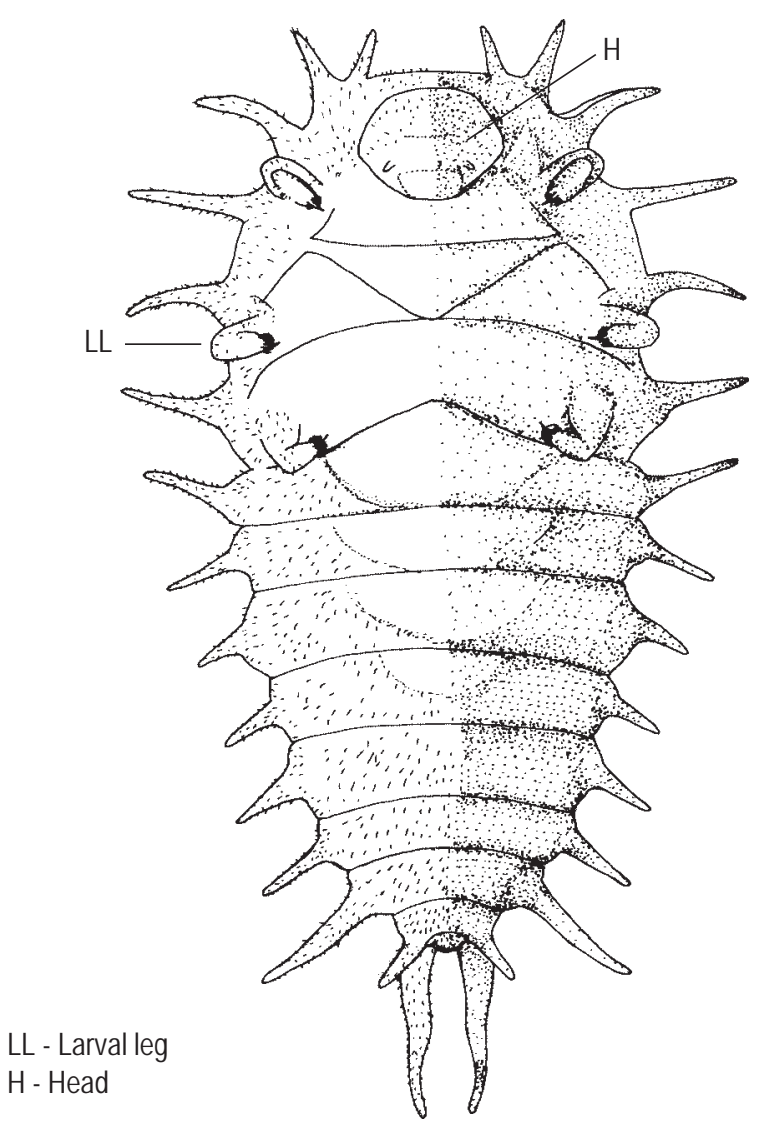

Figure 3. Ventral view of the larva covered by setae

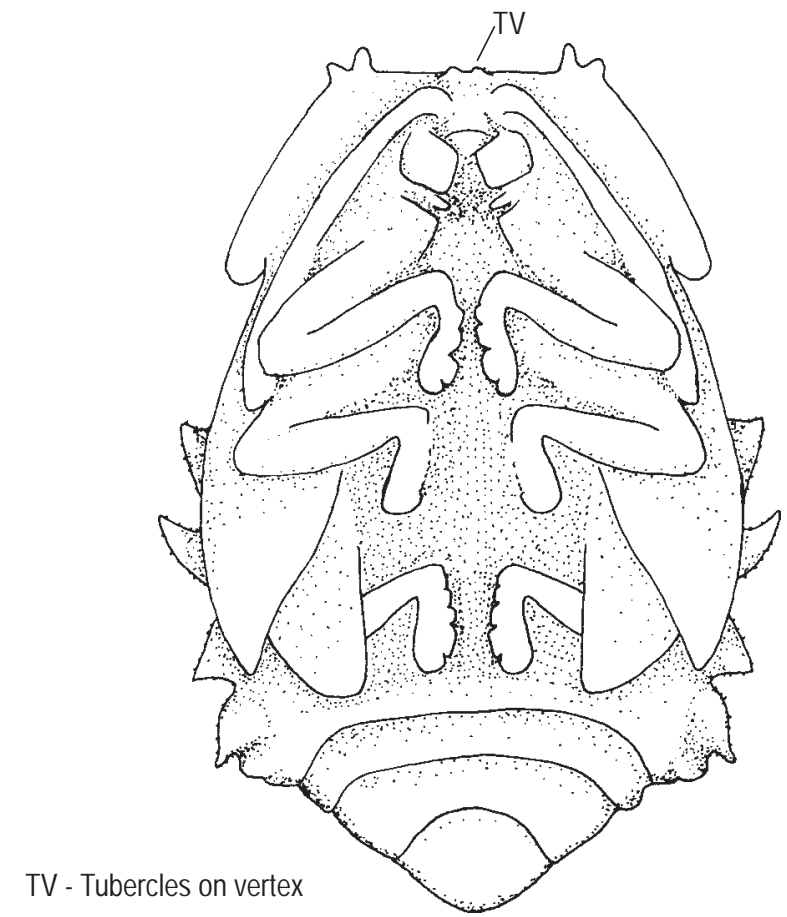

Figure 5. Ventral view of the pupa 